\title{
AS ANALOGIAS NA REVISTA DE DIVULGAÇÃO CIENTÍFICA CIÊNCIA HOJE DAS CRIANÇAS
}

\author{
The analogies in the popular science magazine \\ Ciência Hoje das Crianças
}

Leandro Londero da Silva ${ }^{1}$

Naida Lena Pimentel ${ }^{2}$

Eduardo Terrazzan ${ }^{3}$

\begin{abstract}
Resumo: Investigamos a frequência de utilização de analogias nos artigos da revista de divulgação científica brasileira Ciência Hoje das Crianças. Nos 143 números publicados até fevereiro de 2004, encontramos 136 apresentações analógicas em 88 artigos, e as classificamos segundo três dos critérios sugeridos por Curtis e Reigeluth (1984): 44,7\% são do tipo funcional; 86,5\%, do verbal, e 51,1\% têm análogo trabalhado durante o desenvolvimento do alvo. Constatamos que o número de analogias variou de maneira não uniforme, sendo que a maior frequência de utilização ocorreu em 1995, quando mapeamos trinta apresentações. Quanto ao grau de concordância com o modelo Teaching with Analogies, verificamos que o estabelecimento de correspondências entre alvo e análogo não é contemplado em 58,9\% dos casos, e a identificação dos limites de validade do análogo não o é em 92,2\%.
\end{abstract}

Palavras-chave: Analogias. Ensino de Ciências. Divulgação científica. Ciência Hoje das Crianças.

\begin{abstract}
We investigated the frequency of use of analogies in the articles in the magazine Ciência Hoje das Crianças. In the 143 issues published until February 2004, we found 136 analogies in 88 articles, and we classified them according to three of the criteria suggested by Curtis e Reigeluth (1984): 44,7 \% represent the functional type; $86,5 \%$, the verbal type and $51,1 \%$ have an analog worked during the development of the target. We observed that the number of analogies varied in a non-uniform manner, and that the largest analogy use occurred in 1995 once we mapped 30 presentations in this year. With regard to the level of agreement with the Teaching with Analogies model, we verified that the establishment of correspondences between the target and analog is not considered in 58,9\%, and the identification of the limits of validity of the analog does not occur in $92,2 \%$.
\end{abstract}

Keywords: Analogies. Science education. Scientific popularization. Ciência Hoje das Crianças.

\footnotetext{
${ }^{1}$ Licenciado em Física, doutorando em Educação. Docente, Departamento de Ciências Exatas, Universidade Federal de Alfenas. Alfenas, MG, Brasil. <llondero@bol.com.br>

${ }^{2}$ Licenciada em Química e Farmácia, Mestre em Química. Docente, Centro de Ciências Naturais e Exatas, Universidade Federal de Santa Maria (UFSM). Santa Maria, RS, Brasil. <naidalp@terra.com.br>

${ }^{3}$ Licenciado e Bacharel em Física, doutor em Educação. Docente, Departamento de Metodologia do Ensino do Centro de Educação, UFSM. Santa Maria, RS, Brasil. <eduterrabr@yahoo.com.br>

${ }^{1}$ Universidade Federal de Alfenas - Instituto de Ciências Exatas

Rua Gabriel Monteiro da Silva, 700

Centro - Alfenas, MG

$37.130-000$ 


\section{As analogias na construção do conhecimento científico e na aprendizagem de ciências}

Partimos da premissa de que a utilização de analogias possibilita a construção de conceitos científicos. Seu uso favorece a compreensão/entendimento de conceitos que, na maioria dos casos, são considerados difíceis pelos alunos.

Lawson (1993) claramente explicou a utilidade das analogias no prelúdio ao volume especial do Journal of Research in Science Teaching. Neste prelúdio o autor pergunta Como um professor pode ajudar os alunos a adquirirem entendimento de conceitos teóricos? Para a pergunta, o autor responde: "Pelo menos parte da resposta, eu penso, é pelo uso de analogias. Estudantes não podem experimentar a natureza de átomos diretamente. Mas eles podem e experimentam bolas de vários tamanhos" (LAWSON, 1993, p. 1214).

Segundo esse autor, existem, pelo menos, dois tipos de conceitos científicos. Conceitos como variação fenotípica, sólido, líquido e gás são descritivos porque existem exemplares perceptíveis no ambiente. Assim, quando os estudantes precisam de exemplos para compreenderem conceitos descritivos, o professor pode mostrar vários.

Por outro lado, exemplares perceptíveis para conceitos como átomo, gene, quark, e graviton não existem no ambiente. $\mathrm{O}$ significado de tais conceitos não pode ser derivado de nossas percepções de objetos, eventos, ou situações. Ao invés, os significados deles/delas vêm das imaginações de cientistas. Os conceitos são "invenções" criativas e existem como parte de sistemas conceituais explicativos. As invenções podem ou não existir de fato no mundo lá fora. Tais conceitos são chamados de teóricos por Lawson (1993).

Ainda, como funções das analogias, podemos citar as descritas por Godoy (2002), são elas: a) explicativa - quando a analogia cumpre a função de assimilar o novo em termos de coisas conhecidas, evitando que as novas premissas resultem estranhas; b) popularizar - pode ser considerada como uma função de explicar, porém, nos últimos anos, tem adquirido importância muito grande; c) generalizar - relacionar coisas diferentes, que sirvam de base a um processo de generalização. Se estabelecermos que vários problemas são análogos, podemos usar o processo de indução para extrair conclusões a partir destes casos análogos; d) formular hipóteses - gerar novas hipóteses de trabalho para serem investigadas. É uma função crucial no contexto do descobrimento; e) modelar - em alguns casos, uma analogia provê um modelo para um problema. É uma maneira de solucionar um problema à espera de que surja uma melhor solução no futuro, ou uma solução com maior justificação; f) validar - validar conceitos em um campo, utilizando uma transferência deste campo mediante o uso de analogias. Em geral, aqui se transferem os valores reconhecidos de uma teoria para outra; g) predizer - usar analogias para realizar predições de um problema utilizando predições de outro problema; $h$ ) estruturar - dar estrutura a um problema baseando-se na estrutura de outro problema.

Nosso foco de estudo centra-se na função explicativa das analogias para o ensino de conceitos científicos, ou seja, quando elas cumprem a função de assimilar novos conteúdos em termos de coisas conhecidas, evitando que estes novos conteúdos resultem estranhos aos alunos.

Ainda, para os interesses dessa pesquisa, uma analogia é definida como uma comparação entre dois conceitos/fenômenos/assuntos que mantém certa relação de semelhança entre ambos. Os elementos que constituem uma analogia são: o análogo (representa o conhecimento já familiar, é aquele em que há diferenças bem nítidas), o alvo (representa o conheci- 
As analogias na revista de divulgação ...

mento menos familiar ou desconhecido) e as relações analógicas (conjunto de relações que se estabelecem, sejam elas de semelhança ou de diferença, permitindo a compreensão/entendimento do alvo).

\section{As analogias em textos escritos}

Nas últimas décadas, as pesquisas envolvendo o uso de analogias alcançaram um número considerável. Muitas delas analisaram como as analogias são apresentadas em textos didáticos, especificando, por exemplo, os tipos de analogias utilizadas, as suas posições no texto, objetivo de inserção e a forma de organização das apresentações (CURTIS; REIGELUTH, 1984; GLYNN apud DUIT, 1991; THIELE; TREAGUST, 1995).

Apresentam-se, brevemente, pesquisas cujos autores tiveram como propósito investigar o uso de analogias em textos escritos. Os resultados destes estudos servirão de base para possíveis comparações com os obtidos em nossa investigação.

Um dos trabalhos pioneiros em investigar o uso de analogias em textos didáticos é o de Curtis e Reigeluth (1984), uma vez que trabalhos posteriores (TREAGUST et al., 1992; THIELE; TREAGUST, 1995) fazem referência a esta investigação. Sendo assim, destacamos sua importância e o comentamos a seguir.

Curtis e Reigeluth (1984) analisaram, em estudo quantitativo, as analogias presentes em 26 livros de ciências, sendo: dez de Biologia, seis de Ciências Gerais, quatro de Química, três de Física, dois de Ciências da Terra e um de Geologia. Foram mapeadas 216 apresentações analógicas, com uma média de 8,3 analogias por livro.

As analogias mapeadas foram analisadas de acordo com algumas categorias de registro, descritas a seguir.

a) Tipo de relação analógica (estrutural, funcional e estrutural-funcional) - Se o análogo e o alvo compartilham atributos estruturais e funcionais ou ambos. A relação é dita estrutural quando análogo e alvo apresentam a mesma aparência física geral. A relação é dita funcional quando análogo e alvo apresentam funções similares. A relação é dita estruturall funcional quando combina relações estruturais e funcionais. Nos textos analisados pelos autores, a maioria das relações analógicas foi categorizada como funcionais (152 ou 70\%), 53 como estruturais $(25 \%)$ e somente 11 como estrutural-funcionais $(5 \%)$.

b) Formato da apresentação (verbal e pictórica-verbal) - A apresentação é dita verbal quando é expressa somente em palavras. A apresentação é dita pictórica-verbal quando é expressa por palavras e reforçada por figuras do análogo, que podem ser tanto um desenho como uma fotografia.

As analogias pictórico-verbais proveem uma visualização ao estudante, enquanto analogias verbais exigem que os estudantes produzam suas próprias visualizações. A maioria das analogias mapeadas era verbal (182 ou 84\%). Somente 34 (16\%) combinaram figuras e texto.

c) Nivel de enriquecimento (simples, enriquecidas e estendidas) - Uma apresentação analógica é dita simples quando o análogo é conectado ao alvo através de expressões do tipo "é como", "pode ser comparado a", "é semelhante a". Das 216 analogias, 14 (6\%) foram categorizadas como simples. Por outro lado, uma apresentação analógica é dita enriquecida quando alguns dos atributos compartilhados são explicitados, podendo incluir as limitações da relação 
analógica. Os autores classificaram 175 das analogias, ou seja, 81\% como enriquecidas com vários níveis de correspondências e limitações. Uma apresentação analógica é dita estendida quando várias correspondências de um único análogo são usadas para ensinar mais de um alvo ou quando vários análogos eram usados para explicar um único alvo. Somente 27 analogias $(13 \%)$ foram consideradas estendidas.

d) Nivel de abstração (concreta-concreta, abstrata-abstrata e concreta-abstrata). O conteúdo do análogo e do alvo pode ser categorizado como concreto ou como abstrato. Há três combinações possíveis: concreta-concreta (em que análogo e alvo são de natureza concreta), abstrata-abstrata (em que análogo e alvo são de natureza abstrata), e concreta-abstrata (em que o análogo é de natureza concreta e alvo é de natureza abstrata). Como era de se esperar, nenhuma analogia abstrata-concreta foi mapeada nos livros inspecionados, visto que o objetivo de uma analogia é ajudar a explicar conteúdos abstratos ou difíceis. Já que as analogias promovem uma ponte entre o familiar e o não familiar, entre um conteúdo simples e um complexo ou difícil, a vasta maioria das analogias encontrada foi categorizada como: concretas-abstratas (178 ou 82\%), 26 (12\%) como concretas-concretas, e 12 (6\%) como abstratas-abstratas.

e) Posição do análogo em relação ao alvo (antes, durante e depois). A posição do análogo pode variar. $\mathrm{O}$ análogo pode ser apresentado no início, durante ou no final da instrução. $\mathrm{O}$ análogo pode ser apresentado no início da instrução, como um organizador avançado (AUSUBEL apud CURTIS; REIGELUTH, 1984). Neste sentido, poderia promover o conhecimento necessário para aprendizagem de um conceito novo, pouco conhecido. Por outro lado, o análogo pode ser apresentado em algum lugar durante a instrução, em um ponto no qual o conteúdo esta se tornando muito abstrato, difícil para o estudante. Neste caso, ele estará atuando como um ativador embutido. Finalmente, a analogia pode aparecer no final da instrução de um tópico, atuando como pós-sintetizador da informação precedente. Das 216 analogias, cinquenta (23\%) foram posicionadas como organizadores prévios, 163 ou $76 \%$ foram posicionadas como ativadores embutidos e apenas três (1\%) como pós-sintetizador.

f) Orientaçoes ao usar analogias - Geralmente é aceito, particularmente pelos autores de livros didáticos, que os estudantes sabem sobre o análogo a ser utilizado e sobre a estratégia cognitiva do pensamento analógico. Isto pode ser explicado tendo em vista que, das 216 analogias, em 106 (49\%) os autores de livros didáticos não fizeram nenhuma tentativa de descrever o análogo ou a estratégia cognitiva depois de apresentarem o alvo. No entanto, esta pressuposição de que os alunos já conhecem o análogo e a estratégia cognitiva pode ser incorreta. Em casos em que o análogo não é familiar para os alunos, seria melhor explicar ou descrever o análogo. Se o análogo é familiar, mas complexo, seria mais benéfico revisá-lo antes de usar a analogia. Identificar a analogia expressamente como uma estratégia cognitiva foi outra técnica usada pelos autores de livros didáticos. Neste sentido, esclareciam, aos alunos, que uma comparação entre algo não familiar e algo familiar iria ocorrer no intuito de ajudálos a entender o conceito não familiar. Em alguns casos, os autores dos livros didáticos explicavam o análogo e também identificavam a estratégia (17 ou 8\% das analogias).

Com base no estudo, os autores chegaram à conclusão de que: a) analogias são frequentemente usadas em uma variedade de modos nos textos; b) analogias assumem uma variedade de estruturas e posições nos textos; c) o tipo e quantia de explicações incluídas dentro das analogias variam e podem depender da preferência individual do autor, do nível de estudante e/ou da natureza da própria analogia. 
As analogias na revista de divulgação ...

Glynn apud Duit (1991), analisando as analogias usadas em 43 livros didáticos de ciências da escola básica, média e universitária, encontrou muitos exemplares de analogias simples. A análise realizada por este autor foi de natureza interpretativa, ou seja, não foi baseada em categorias desenvolvidas formalmente. No seu estudo constatou que as analogias mais elaboradas eram relativamente raras em livros de ciências do Ensino Fundamental, sendo que apareciam em maior quantidade em livros didáticos universitários de Física ou em livros científicos de Física.

Thiele e Treagust (1995) examinaram oito livros de ensino de Química usados em salas de aula em escolas secundárias australianas para determinar a extensão e natureza das analogias. Foram catalogadas 62 analogias. Especificamente, o estudo investigou: a) o conteúdo do conceito-alvo, b) a extensão do mapeamento feita pelo autor, c) evidência de explicações adicionais do análogo, d) evidências de estratégias de identificação, e) se era verbal ou pictórica, f) a presença de declaração das limitações ou advertências.

Em uma segunda etapa, realizaram entrevistas semiestruturadas com os autores dos 08 livros didáticos. Nelas solicitavam as visões dos autores quanto: ao uso, às razões para inclusão ou exclusão de analogias em materiais instrutivos, às necessidades de utilização de analogias nos livros, interesse pessoal para o uso de determinadas analogias e às mudanças propostas em edições posteriores do próprio livro.

Os resultados revelaram que é frequente o uso de analogias pelos autores, porém a frequência variou amplamente entre os livros analisados. Com isso, os investigadores desejavam conhecer que papel teve a natureza do conteúdo na inclusão das analogias.

Verificaram que das 62 analogias, 12 delas (19\%) estão relacionadas à estrutura atômica. A natureza microscópica destes conceitos indica que as analogias podem ter sido incluídas, sobretudo, como uma ferramenta para ajudar na visualização. Os autores reconhecem que uma alternativa para a visualização de conceitos microscópicos seria o uso de analogias pictóricas, o que está descartado já que isto elevaria o custo do livro, pois, as editoras pedem que o custo seja o mínimo, consecutivamente o espaço para escrita fica resumido.

Thiele e Treagust (1995) também usaram o critério Nível de Enriquecimento de Curtis e Reigeluth (1884) para classificar as analogias, encontrando 23 analogias (37\%) do tipo simples, 26 (42\%) enriquecidas e $13(21 \%)$ estendidas.

Outro fator a ser levado em consideração pelos autores de livros didáticos refere-se à familiaridade dos análogos empregados nas analogias. Para suprir esta deficiência, Thiele e Treagust (1995) propõem que uma estratégia que pode ser empregada por autores é proverem explicações adicionais do análogo e seus atributos pertinentes.

Nos livros analisados, a maioria das analogias $(43,69 \%)$ incluiu alguma explicação do análogo. Alguns autores indicam que é função do professor promover explicações adicionais do que consta nos textos. No entanto, não podemos tomar como pressuposto a explicação adicional do professor para a inclusão de analogias.

No que se refere aos limites de validade das analogias, os autores declararam advertências em apenas sete das 62 analogias. Isto mostra que os autores consideram que os estudantes são capazes de efetuar transferências analógicas ou que é função do professor, no andamento de suas atividades em sala de aula, ajudar nestas considerações. 
Silva, L. L.; Pimentel, N. L.; Terrazzan, E.

\section{As analogias em textos de divulgação científica para crianças}

A divulgação científica está cada vez mais presente no cotidiano das crianças, sendo feita de diversas formas, como, por exemplo, programas de televisão (O Mundo de Beakman, Minuto Científico, Globo Ciência, Ciência Travessa), e publicações em revistas (Disney Explora, Dever de Casa, Lição de Casa, Recreio, Ciência Hoje das Crianças).

Essas revistas, objetivando divulgar a produção científica, procuram veicular textos com linguagem familiar e informal, acessível ao público infantil. Nelas, nota-se que os textos tratam com naturalidade o conhecimento científico mediante a abordagem de aplicações da tecnologia, aparatos tecnológicos e de fenômenos presentes no cotidiano das crianças.

Um fator extremamente relevante a ser levado em conta, na hora da elaboração de qualquer texto de divulgação científica, diz respeito à linguagem utilizada.

$\mathrm{Na}$ literatura, encontram-se autores que afirmam ser fundamental o uso de analogias visando tornar as exposições mais claras e atraentes aos leitores. Mora (1998), por exemplo, constatou, com base em uma análise de diversos livros e artigos de ciências, que os textos de divulgação científica que melhor atendem ao objetivo de informar e atrair o leitor reúnem um ou vários dos seguintes recursos: apoio na história e na tradição, referência à cultura popular, uso de ironia e humor, uso de analogias e metáforas, vínculo com o cotidiano, entre outros. Estes recursos são também apontados por Massarani (1999) como relevantes para serem levados em conta na elaboração de um texto de divulgação científica. Esta autora, ao argumentar sobre a produção de textos de divulgação científica, afirma: "Como em qualquer publicação de divulgação científica, é crucial que, em uma revista para crianças, não se usem jargões científicos. É fundamental, também o uso de analogias com situações simples do cotidiano da criança" (MASSARANI, 1999, p. 64, grifo nosso).

Para Sousa (2000), a linguagem utilizada no texto de divulgação científica tende a se aproximar da linguagem do cotidiano, apoiando-se em metáforas e analogias para tornar as exposições mais claras. Nesse mesmo sentido, Encarnação (2001) também afirma que comparações são recursos bastante utilizados, na tentativa de tornar artigos e matérias mais leves e palatáveis para as crianças.

Portanto, as analogias podem ser úteis para facilitar a compreensão de assuntos, conceitos ou fenômenos, na medida em que utilizam situações já conhecidas ou mais familiares para favorecerem a compreensão de situações não conhecidas ou menos familiares, mediante comparações.

\section{Objetivos e questões norteadoras}

Este trabalho partiu das considerações mencionadas anteriormente e da constatação da ausência, na literatura consultada, de pesquisas que analisem as apresentações analógicas em textos de divulgação científica destinados ao público infantil.

Ainda, tendo em vista que a Ciência Hoje das Crianças, mesmo não sendo necessariamente destinada para a sala de aula, é distribuída pelo governo federal a muitas escolas públicas, por meio de programas de apoio à leitura, torna-se fundamental analisar os limites e as potencialidades das analogias identificadas na revista para a aprendizagem de seus leitores. 
As analogias na revista de divulgação ...

Perante isso, o foco desse estudo concentra-se no mapeamento e na análise das apresentações analógicas encontradas nos artigos publicados na revista Ciência Hoje das Crianças.

Quatro questões que parecem relevantes permearam este estudo. São elas: a) Qual a frequência de utilização de analogias nos artigos da revista? b) Qual o grau de explicitação das relações analógicas e das limitações das analogias? c) Em que medida os análogos utilizados podem ser considerados familiares às crianças? d) Qual a forma de apresentação das analogias utilizadas nos artigos?

Para responder estas questões, alguns caminhos foram percorridos. No próximo item apresentam-se comentários sobre os passos de desenvolvimento do estudo.

\section{Metodologia da investigação}

Para o desenvolvimento deste trabalho, selecionou-se a revista de divulgação científica Ciência Hoje das Crianças, publicada pela Sociedade Brasileira para o Progresso da Ciência (SBPC). Adotou-se como critério, para a seleção, a revista veicular majoritariamente artigos de divulgação científica e a disponibilidade de todos os exemplares publicados até fevereiro de 2004.

Lançada em dezembro de 1986, a revista é publicada há 18 anos, com periodicidade mensal que vem se mantendo constante há 15 anos.

Um dos objetivos da revista é o de estimular a curiosidade das crianças em relação a fenômenos, fatos e métodos das ciências. Ela é elaborada para a faixa etária de sete a quatorze anos. Em geral, os artigos publicados são produzidos por pesquisadores e professores da comunidade científica brasileira.

Inicialmente, mapearam-se as apresentações analógicas mediante a leitura dos textos que compõem cada exemplar, visando responder a primeira questão norteadora deste trabalho. Leram-se 143 números, correspondentes ao período de dezembro de 1986 a fevereiro de 2004, perfazendo um total de 1.022 textos.

Organizaram-se as apresentações analógicas mapeadas em quadros-síntese, incluindo as situações-alvo e análogas contidas no texto original, bem como as relações analógicas pretendidas. Um extrato deste quadro encontra-se no Anexo 1.

Após, agruparam-se as apresentações analógicas segundo as "áreas temáticas" focalizadas pela revista: Ciências Humanas e Sociais, Exatas, Biológicas, da Terra, Saúde, Meio Ambiente, Tecnologia, Cultura, Linguística (Letras e Artes) ${ }^{4}$.

A seguir, realizou-se um mapeamento da frequência das apresentações analógicas por anos de publicação, com o intuito de obtermos informações sobre a frequência das apresentações ao longo do período analisado.

Em continuidade, procurou-se responder a segunda questão norteadora. Para isso analisou-se o grau de concordância das analogias com a versão modificada do modelo TWA

\footnotetext{
${ }^{4}$ Não se consideraram, no estudo, os jogos, experimentos, histórias em quadrinhos, cartas e bate-papo, mas somente as áreas nas quais são publicados artigos.
} 
Silva, L. L.; Pimentel, N. L.; Terrazzan, E.

(Teaching with Analogies), sugeridas por Harrison e Treagust (1993). Este modelo surgiu de uma análise crítica e comparativa sobre a forma como as analogias são apresentadas em diversos livros didáticos.

Decidiu-se analisar as apresentações analógicas nos textos, à luz deste modelo, porque sua estruturação enfatiza que o essencial é a compreensão não apenas das relações analógicas pretendidas, como também a dos limites de validade da analogia utilizada.

Segundo o modelo TWA, para uma utilização adequada de analogias, deve-se procurar seguir uma sequência de seis passos, a saber:

$1^{\circ}$ Passo - Apresentação da "situação-alvo" a ser tratada.

$2^{\circ}$ Passo - Apresentação da "situação análoga" auxiliar.

$3^{\circ}$ Passo - Identificação das características relevantes do análogo.

$4^{\circ}$ Passo - Estabelecimento das correspondências entre o análogo e o alvo.

$5^{\circ}$ Passo - Identificação dos limites de validade da analogia utilizada.

$6^{\circ}$ Passo - Esboço de síntese conclusiva sobre a "situação-alvo".

Registraram-se os dados em uma tabela e foram analisados qualitativamente. Utilizou-se uma escala qualitativa na qual se buscou graduar a concordância de cada apresentação analógica, com os passos do modelo TWA. Nesta escala, utilizou-se a letra "C" para indicar a concordância da apresentação com o passo do modelo, "NC" para indicar a não-concordância, e "P", para indicar a concordância parcial. Veja extrato na Tabela 1.

A seguir, procurou-se responder as duas últimas questões norteadoras. Para isso, as apresentações analógicas foram classificadas em cinco categorias. Uma delas é proposta por Queiroz (2000), a qual se refere ao tipo de analogia utilizada em relação à área de origem do análogo utilizado; as outras quatro foram propostas por Curtis e Reigeluth (1984) e se referem à forma de apresentação de analogias em textos.

Tabela 1. Análise das analogias identificadas na Revista Ciência Hoje das Crianças segundo o modelo TWA.

\begin{tabular}{|c|c|c|c|c|c|c|c|c|c|c|}
\hline \multirow{2}{*}{$\begin{array}{c}\text { Código da } \\
\text { Analogia }\end{array}$} & \multirow{2}{*}{ Ano } & \multirow{2}{*}{ N. } & \multirow{2}{*}{ Data } & \multirow{2}{*}{ Página(s) } & \multicolumn{6}{|c|}{ Passos } \\
\hline & & & & & 1 & 2 & 3 & 4 & 5 & 6 \\
\hline $\mathrm{CHCO1}$ & Não informa & 01 & Não informa & Não informa & C & C & $\mathrm{P}$ & $\mathrm{P}$ & NC & NC \\
\hline $\mathrm{CHCO3}$ & Não informa & 10 & Não informa & 06 & C & $\mathrm{C}$ & C & C & NC & C \\
\hline $\mathrm{CHCO} 4$ & $1990 / 1991$ & 19 & Dez/Jan & 07 & C & $\mathrm{C}$ & NC & $\mathrm{P}$ & NC & C \\
\hline $\mathrm{CHC08}$ & 1990/1991 & 19 & Dez/Jan & 11 & C & $\mathrm{C}$ & NC & $\mathrm{NC}$ & NC & NC \\
\hline $\mathrm{CHCO9}$ & 1990/1991 & 19 & Dez/Jan & 16 & C & $\mathrm{C}$ & NC & $\mathrm{NC}$ & NC & C \\
\hline $\mathrm{CHC} 10$ & 1990/1991 & 19 & Dez/Jan & 16 & C & C & $P$ & $P$ & NC & $\mathrm{C}$ \\
\hline $\mathrm{CHC} 12$ & 1990/1991 & 19 & Dez/Jan & 16 & C & C & $P$ & $\mathrm{P}$ & NC & $\mathrm{C}$ \\
\hline $\mathrm{CHC13}$ & 1991 & 22 & Jun/Jul & $14-16$ & C & C & NC & NC & NC & $\mathrm{C}$ \\
\hline $\mathrm{CHC} 14$ & 1992 & 28 & Ago/Set & 05 & C & $\mathrm{C}$ & C & C & NC & NC \\
\hline $\mathrm{CHC} 15$ & 1992 & 29 & Out/Nov/Dez & 03 & C & $\mathrm{C}$ & NC & NC & NC & C \\
\hline $\mathrm{CHC} 16$ & 1994 & 35 & Jan/Fev & $04-05$ & C & $\mathrm{C}$ & NC & $\mathrm{P}$ & NC & $\mathrm{C}$ \\
\hline $\mathrm{CHC} 21$ & 1994 & 39 & Junho & 25 & C & $\mathrm{C}$ & NC & $\mathrm{P}$ & $\mathrm{P}$ & NC \\
\hline $\mathrm{CHC} 23$ & 1994 & 41 & Ago/Set & 03 & $\mathrm{NC}$ & $\mathrm{C}$ & NC & $\mathrm{P}$ & NC & C \\
\hline $\mathrm{CHC} 24$ & 1994 & 41 & Ago/Set & 13 & C & $\mathrm{C}$ & NC & NC & NC & $\mathrm{NC}$ \\
\hline $\mathrm{CHC} 25$ & 1994 & 42 & Out & 03 & C & $\mathrm{C}$ & NC & $\mathrm{NC}$ & NC & $\mathrm{P}$ \\
\hline
\end{tabular}


Categoria proposta por Queiroz (2000):

1 Analogias internas à própria área do conhecimento (categoria redefinida) - recuperam conceitos e fenômenos já trabalhados anteriormente.

Categorias propostas por Curtis e Reigeluth (1984), já definidas anteriormente:

2 Tipo de relação analógica (estrutural, funcional, estrutural-funcional);

3 Formato da apresentação (verbal, pictórica-verba);

4 Posição do análogo em relação ao alvo (início, durante, depois);

5 Nível de enriquecimento (simples, enriquecidas, estendidas).

Finalmente, analisaram-se os resultados obtidos. Após algumas considerações sobre o desenvolvimento do estudo, passam-se a relatar os resultados encontrados.

\section{Resultados e análises}

\section{Frequência geral de apresentações analógicas}

Nos 143 números da revista, encontrou-se um total de 88 artigos que utilizam o recurso analógico, e, neles, 136 apresentações analógicas, ou seja, uma média de quase uma analogia por edição da revista. Este índice pode ser considerado pequeno em comparação com o número total de páginas de cada edição.

Constatou-se que alguns autores utilizaram várias delas em um mesmo texto, para explicar conceitos diferentes.

\section{Frequência de apresentações analógicas nas áreas temáticas}

A Tabela 2 apresenta a frequência de apresentações analógicas utilizadas por áreas temáticas da revista, em relação ao total de apresentações mapeadas nos artigos que fazem uso deste recurso, e o Gráfico 1 apresenta os índices porcentuais.

Tabela 2. Frequência das apresentações analógicas por "área temática".

\begin{tabular}{lc}
\multicolumn{1}{c}{ Área } & Frequência \\
\hline Ciências Biológicas & 74,0 \\
Ciências Exatas & 36,0 \\
Ciências da Terra & 2,0 \\
Ciências da Saúde & 8,0 \\
Meio Ambiente & 7,0 \\
Tecnologia & 5,0 \\
Cultura & 2,0 \\
Linguística (Letras e Artes) & 0,0 \\
Ciências Sociais e Humanas & 2,0 \\
Total & 136,0 \\
\hline
\end{tabular}


Silva, L. L.; Pimentel, N. L.; Terrazzan, E.

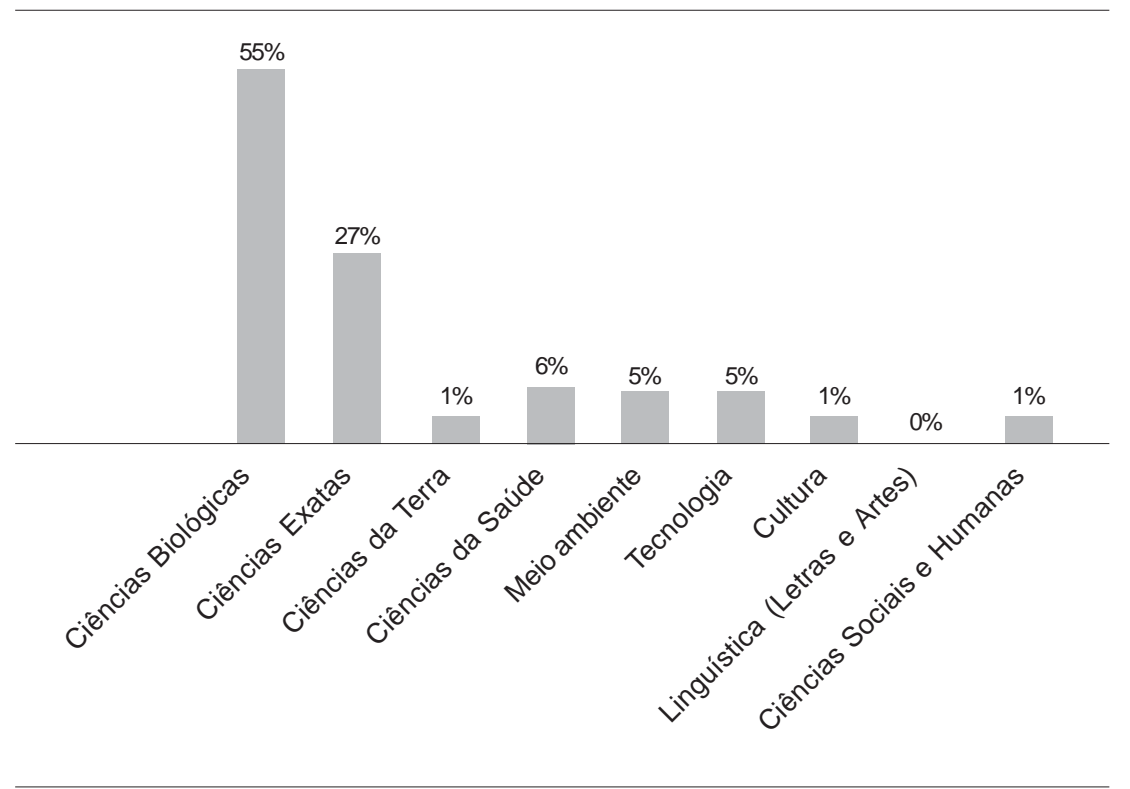

Gráfico 1. Porcentagem das apresentações analógicas por "área temática".

Considerando o número de apresentações analógicas presentes por áreas temáticas, a observação da Tabela 2 e do Gráfico 1 permite evidenciar que a área de Ciências Biológicas é aquela que aparece com o maior percentual de apresentações analógicas (55\%), em seguida, aparecem as Ciências Exatas (27\%). Os menores índices de utilização foram constatados nos temas relacionados a Cultura, Ciências da Terra e Sociais e Humanas, sendo que não mapeamos nenhuma apresentação para textos que fazem referência a Linguística.

Como eram esperados, os índices aqui encontrados diferem dos de Curtis e Reigeluth (1984), uma vez que esses autores trabalham com livros temáticos e a revista Ciência Hoje das Crianças com todos os temas ou vários em um mesmo exemplar.

No estudo realizado por Curtis e Reigeluth (1984), os autores obtiveram uma média de 6,3 para analogias nos livros de Biologia, 6,5 para Ciências Gerais, 8,3 para os de Física e 14,3 para os de Ciências da Terra. A observação da Tabela 2 permite afirmar que, no estudo aqui relatado, os textos destinados às Ciências Biológicas lideraram a frequência de uso de analogias $(54,5 \%)$, ou seja, esta "área temática" concentrou mais da metade das analogias identificadas no total de edições investigadas. Isso talvez possa ser justificado pela revista publicar mais artigos com conteúdos biológicos.

\section{Frequência de apresentações por ano de publicação}

A Tabela 3 mostra os índices absolutos e relativos das apresentações analógicas por ano de publicação, em relação ao total de apresentações mapeadas nos artigos que fazem uso deste recurso. 
As analogias na revista de divulgação ...

Tabela 3. Frequência das apresentações analógicas por ano de publicação.

\begin{tabular}{lrr}
\hline \multirow{2}{*}{ Ano } & \multicolumn{2}{c}{ Frequência } \\
\cline { 2 - 3 } & f & \multicolumn{1}{c}{$\%$} \\
\hline$\left[1986^{5}-1989\right]$ & 3 & 2,20 \\
1990 e jan. 19916 & 9 & 6,7 \\
1991 fev. a dez. & 1 & 0,73 \\
1992 & 2 & 1,46 \\
1993 & 0 & 0,00 \\
1994 & 11 & 8,08 \\
1995 & 30 & 22,05 \\
1996 & 12 & 8,82 \\
1997 & 6 & 4,41 \\
1998 & 16 & 11,76 \\
1999 & 3 & 2,20 \\
2000 & 2 & 1,46 \\
2001 & 14 & 10,30 \\
2002 & 11 & 8,08 \\
2003 & 15 & 11,02 \\
fev. 2004 & 1 & 0,73 \\
Total & 136 & 100,0 \\
\hline
\end{tabular}

Esperava-se encontrar um aumento na frequência de uso de apresentações analógicas com o passar dos anos, porém, isto não se verificou. Observando a Tabela 3, é fácil constatar que o número de apresentações analógicas varia de maneira não uniforme ao longo do período investigado, sendo que a maior frequência de utilização de apresentações analógicas ocorreu em 1995, no qual mapeamos trinta apresentações.

\section{Grau de concordância das apresentações analógicas com o modelo TWA}

O resultado da análise das apresentações analógicas encontradas nos textos à luz do modelo TWA, encontra-se na Tabela 4 e no Gráfico 2, que mostram o grau de concordância delas com os passos propostos pelo modelo.

Tabela 4. Grau de concordância das analogias com os passos do modelo TWA.

\begin{tabular}{|c|c|c|c|c|c|c|c|c|c|c|c|c|}
\hline \multirow{3}{*}{$\begin{array}{l}\text { Grau de concordância } \\
\text { com os passos } \\
\text { do modelo twa }\end{array}$} & \multicolumn{12}{|c|}{ Passos } \\
\hline & \multicolumn{2}{|c|}{1} & \multicolumn{2}{|c|}{2} & \multicolumn{2}{|l|}{3} & \multicolumn{2}{|c|}{4} & \multicolumn{2}{|c|}{5} & \multicolumn{2}{|c|}{6} \\
\hline & $\mathbf{f}$ & $\%$ & f & $\%$ & f & $\%$ & $\mathbf{f}$ & $\%$ & $f$ & $\%$ & $f$ & $\%$ \\
\hline Contempla & 129 & 95 & 134 & 98,5 & 34 & 25 & 22 & 16 & 2 & 1,5 & 78 & 57 \\
\hline Contempla parcialmente & 3 & 2 & 1 & 0,75 & 17 & 12,5 & 31 & 23 & 4 & 3 & 5 & 4 \\
\hline Não contempla & 4 & 3 & 1 & 0,75 & 85 & 62,5 & 83 & 61 & 130 & 95,5 & 53 & 39 \\
\hline
\end{tabular}

${ }^{5}$ Identificamos este ano em Sousa (2000).

${ }^{6}$ Em 1990, o último fascículo (dezembro) incluiu, também, janeiro de 1991. 
Silva, L. L.; Pimentel, N. L.; Terrazzan, E.

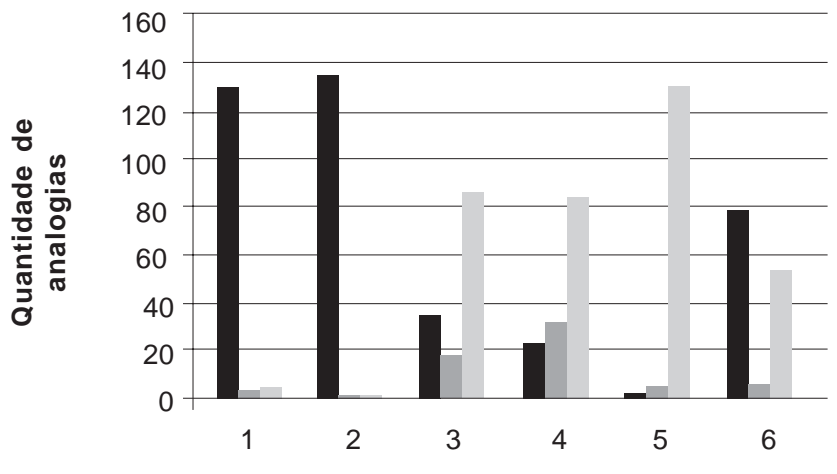

Contempla o passo do modelo

Contempla parcialmente o passo do modelo Não contempla o passo do modelo

Número do passo

Gráfico 2. Porcentagem do grau de concordância das analogias com os passos do modelo TWA.

Com base nos dados contidos na Tabela 4 e no Gráfico 2, vemos que:

A expressiva maioria das apresentações analógicas segue o passo 1 (95\%) e o passo 2 $(98,5 \%)$ do modelo (respectivamente, introduzir o conceito-alvo e o conceito análogo);

. o passo 3 do modelo (identificar as características relevantes do análogo) é contemplado em apenas $25 \%$ das apresentações analógicas;

. o passo 4 é contemplado em apenas $16 \%$ e o passo 5 N $\tilde{A O}$ é contemplado em $95,5 \%$. Isto mostra que a grande maioria das apresentações analógicas utilizadas não apresenta uma discussão aprofundada dos elementos envolvidos nas relações analógicas, o que é preocupante, pois favorece a transferência de características que não são equivalentes de um domínio para o outro;

- a retomada final do alvo (passo 6) ocorre em um pouco mais da metade das apresentações analógicas (57\%).

Os percentuais obtidos para o grau de concordância das analogias com os passos do modelo TWA, em geral, podem ser comparados aos obtidos por Thiele e Treagust (1995), visto que a maioria das apresentações analógicas identificadas nas duas investigações incluiu alguma explicação do análogo.

Tendo em vista que a maior parte das analogias identificadas não contempla os passos 3, 4 e 5 do modelo TWA, podemos inferir que, assim como no estudo de Thiele e Treagust (1995), os autores dos textos publicados na Ciência Hoje das Crianças, e que se utilizam do recurso analógico, podem talvez pensar que é função do professor promover explicações adicionais às que constam nos textos; entre estas explicações estão: a identificação das características relevantes do análogo, o estabelecimento de correspondências entre análogo e alvo, sejam elas de semelhança ou de diferença, e a identificação dos limites de validade da analogia.

Ainda, que os estudantes são capazes de efetuar transferências analógicas ou que é função do professor, no andamento de suas atividades em sala de aula, ajudar nestas considerações (THIELE; TREAGUST, 1995). Mas, para que estas suposições sejam confirmadas, 
As analogias na revista de divulgação ...

teríamos de realizar um estudo junto aos autores, da mesma maneira como fizeram Thiele e Treagust (1995). No entanto, este tipo de análise foge dos objetivos deste estudo.

\section{Categorização das apresentações analógicas de acordo com os critérios propostos por Queiroz (2000)}

$\mathrm{Na}$ categoria "analogias internas à própria área do conhecimento", proposta por Queiroz (2000), foram encontradas 29 apresentações, correspondendo a 21,5\%, ou seja, 78,5\% referem-se a análogos extraídos da vivência cotidiana das crianças. Levando-se em conta que, para uma analogia funcionar bem, o análogo deve ser familiar ao leitor, surpreendeu-nos que a publicação analisada, destinada a crianças, apresente aquele percentual, que, no caso, nos parece bastante elevado.

\section{Categorização das apresentações analógicas de acordo com os critérios propostos por Curtis e Reigeluth (1984)}

A Tabela 5 apresenta as frequências das apresentações analógicas nas diversas categorias e subcategorias de cada critério segundo Curtis e Reigeluth (1984).

De acordo com os dados presentes na Tabela 5 e no Gráfico 3, as frequências das apresentações analógicas estruturais (35\%) e funcionais (47\%) são superiores à das apresentações analógicas estruturais/funcionais (18,5\%). Os índices encontrados para essa categoria são opostos aos de Curtis e Reigeluth (1984), com exceção das apresentações estruturais/funcionais. No estudo desses autores, a maioria das relações analógicas foi categorizada como funcional (70\%), 25\% como estruturais e apenas 5\% como estruturais-funcionais. Não se encontrou uma possível explicação para os valores obtidos, uma vez que os textos analisados pela pesquisa de Curtis e Reigeluth (didáticos) são de natureza diferente dos aqui estudados (divulgação científica).

Tabela 5. Frequência das apresentações analógicas de acordo com quatro das categorias propostas por Curtis e Reigeluth (1984).

\begin{tabular}{|c|c|c|c|}
\hline \multirow[b]{2}{*}{ Critérios } & \multirow[b]{2}{*}{ Classificação } & \multicolumn{2}{|c|}{ Frequência } \\
\hline & & f & Total \\
\hline \multirow[t]{3}{*}{ Relação analógica } & Estrutural & 48 & \\
\hline & Funcional & 63 & 136 \\
\hline & Estrutural funcional & 25 & \\
\hline \multirow[t]{2}{*}{ Formato da apresentação } & Verbal & 121 & \\
\hline & Pictórico-verbal & 15 & 136 \\
\hline \multirow[t]{3}{*}{ Posição do análogo em relação ao alvo } & Antes & 20 & \\
\hline & Durante & 74 & 136 \\
\hline & Depois & 42 & \\
\hline \multirow{3}{*}{ Nível de enriquecimento } & Simples & 108 & \\
\hline & Enriquecida & 24 & 136 \\
\hline & Estendida & 04 & \\
\hline
\end{tabular}


Silva, L. L.; Pimentel, N. L.; Terrazzan, E.

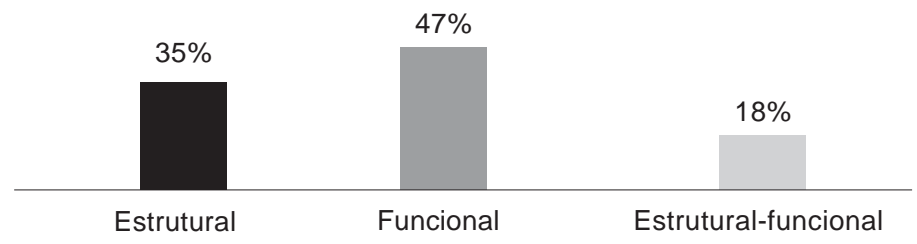

Gráfico 3. Percentual das analogias de acordo com a categoria "relação analógica".

Pensa-se que um número maior de analogias estruturais/funcionais pudesse explorar mais os conceitos/fenômenos presentes nos textos, pois nelas existe um número maior de relações a serem estabelecidas. Um exemplo representativo das apresentações analógicas estruturais/funcionais identificado nos textos é reproduzido a seguir:

As plantas têm um líquido chamado seiva, que é feito, em boa parte, por água. A seiva circula nas plantas assim como o sangue circula no nosso corpo, passando por dentro de tubos. Nos animais, esses tubos são as veias e artérias. Nas plantas, são os vasos condutores, que têm nomes engraçados: os vasos pelos quais a seiva sobe são chamados xilemas e aqueles pelos quais a seiva desce, floemas. (ESQUIBEL, 1996, p. 9)

A observação da Tabela 5 e do Gráfico 4 permite afirmar que, das 136 apresentações analógicas encontradas, $89 \%$ foram classificadas como verbais e somente $11 \%$ como pictóricas-verbais. Apesar de a revista utilizar uma grande quantidade de imagens, poucos são os textos que as utilizam como constituintes de analogias. Para esta categoria, os valores percentuais obtidos são semelhantes aos encontrados por Curtis e Reigeluth (1984), os quais obtiveram $84 \%$ para as analogias do tipo verbal e $16 \%$ para as pictórico-verbais.

Apesar de haver, em nosso estudo, um predomínio de analogias apresentadas na forma verbal, estas, na maioria dos casos, restringem-se a uma simples descrição da situação tratada, ficando a cargo dos leitores o estabelecimento das devidas correspondências e identificação de limitações, como já mencionamos na seção anterior.

O uso mais frequente de apresentações analógicas pictórico-verbais poderia estimular os leitores a "visualizarem" as analogias e, consequentemente, a estabelecerem relações analógicas favorecendo a compreensão das analogias. Porém, como adverte Carneiro (1997), o uso excessivo de imagens não traduz, por si só, os conhecimentos, ou seja, essa autora, em um estudo que focaliza o uso de imagens, faz referência à ideia de que imagens não falam por si sós, há certamente a necessidade de textos explicativos e complementares às imagens. 
As analogias na revista de divulgação ...

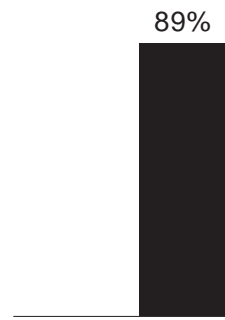

Verbal

Pictórico-verbal

Gráfico 4. Percentual das analogias de acordo com a categoria "formato da apresentação".

Os valores da Tabela 5 e do Gráfico 5 evidenciam que 15\% das apresentações analógicas veiculam o análogo antes do conceito/fenômeno a ser tratado, $54 \%$ durante e $31 \%$ depois. Comparando esses porcentuais como os obtidos por Curtis e Reigeluth (1984), percebe-se que eles assemelham-se, embora não estejamos considerando as noções Ausubelianas de organizador prévio, ativadores embutidos e pós-sintetizador, uma vez que, para tanto, seria necessário um estudo mais aprofundado das posições das analogias nos textos levando em conta as noções acima mencionadas.

Quanto ao nível de enriquecimento, os dados da Tabela 5 e do Gráfico 6 evidenciam que $79 \%$ são analogias do tipo simples, $18 \%$ enriquecidas e somente 3\% estendidas. Mais uma vez, os porcentuais encontrados diferem dos obtidos por Curtis e Reigeluth (1984). Esses autores encontraram porcentuais mais elevados para as analogias enriquecidas (81\%), e para as estendidas (13\%) em comparação com os índices de nosso estudo, que apontou 79\% de analogias do tipo simples. Entretanto, os resultados assemelham-se aos obtidos por Glynn apud Duit (1991), o qual encontrou muitos exemplares de analogias simples, constatando que as analogias mais elaboradas eram relativamente raras em livros de ciências.

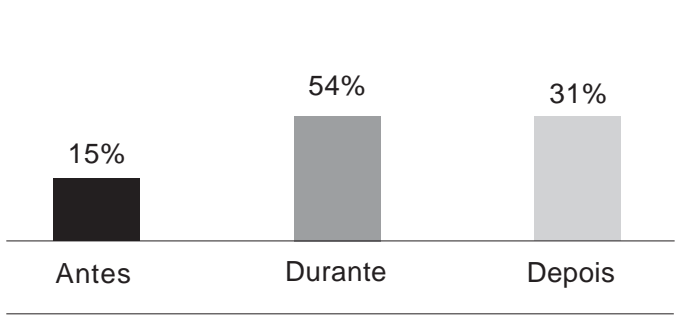

Gráfico 5. Percentual das analogias de acordo com a categoria "posição do análogo em relação ao alvo".

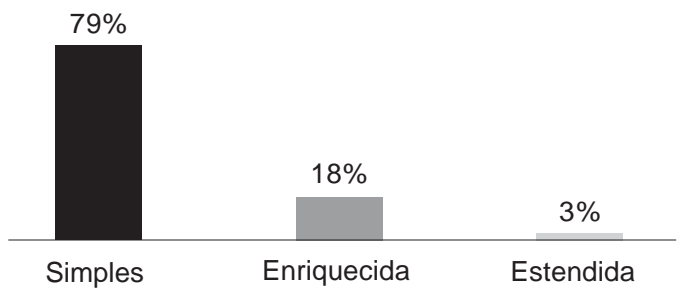

Gráfico 6. Percentual das analogias de acordo com a categoria "nível de enriquecimento". 
Silva, L. L.; Pimentel, N. L.; Terrazzan, E.

A seguir, um trecho de um texto é reproduzido, dos poucos no qual o autor utiliza uma analogia estendida.

O tempo todo, nossos músculos estão trabalhando: quando levantamos da cama, quando colocamos a mochila nas costas, quando corremos atrás do ônibus, quando pulamos, quando chutamos uma bola ufa! Deu até canseira! Ao se contraírem e relaxarem, os músculos botam nosso corpo em movimento! Para entender melhor como eles funcionam, vamos fazer uma comparação com um carro! O que um automóvel precisa para andar? Combustível, em primeiro lugar. Além disso: um motor, pneus e uma carroceria. Com o corpo humano é a mesma coisa. Quer dizer, quase. Afinal, ninguém bebe gasolina, nem tem uma carroceria no lugar das costas! O motor em nosso corpo são os músculos. O combustível para este motor é a energia que conseguimos a partir dos alimentos que comemos. Usando essa energia, os músculos entram em funcionamento. Os ossos, então, fazem o papel dos pneus e da carroceria, pois dão suporte aos músculos. (PINTO, 1999, p. 10)

Este trecho também representa um bom exemplo de apresentação analógica que contempla boa parte dos passos do modelo TWA. A autora, além de introduzir a "situaçãoalvo" a ser tratada (funcionamento dos músculos) e a "situação análoga" auxiliar (motor de um automóvel em movimento), com o uso explícito do termo "vamos fazer uma comparação", explicita correspondências entre o análogo e o alvo (músculos/motor, energia dos alimentos/ gasolina, ossos/pneus e carroceria), identifica limites de validade da analogia com uso das palavras "Quer dižer, quase" e "A final, ninguém", e esboça uma síntese conclusiva sobre a "situação-alvo", não reproduzida neste trecho, além de ser acompanhada de ilustrações do análogo.

Uma vez pontuados os resultados obtidos e respondidas as questões de pesquisa, cabe finalizar este estudo com algumas considerações.

\section{Considerações finais}

Entre os 1.022 textos lidos, somente 88 fazem uso de analogias, correspondendo a $8,5 \%$ do total, o que se considera um baixo índice de utilização. Porém, vale destacar que não se considerou, nesse estudo, o número de páginas, ou seja, os textos diferem em extensão, alguns sendo mais sucintos e outros mais extensos. Pode-se dizer que os resultados obtidos para a frequência de utilização de analogias, nos artigos da Ciência Hoje das Crianças, diferem daqueles encontrados por Curtis e Reigeluth (1984), ou seja, infere-se que, na revista investigada, não é frequente o uso de analogias pelos autores dos textos.

No entanto, não se pode afirmar que o uso mais frequente de analogias poderia tornar as explicações mais claras para as crianças leitoras desta publicação, pois, de acordo com Massarani (1999) - referindo-se a um artigo sobre a química da maionese, escrito por Londres (1997) -, mesmo usando-se analogias e desenhos explicativos, o assunto é bastante 
As analogias na revista de divulgação ...

complicado. Esse fato remete o uso de analogias à natureza do assunto tratado ou ao estilo do autor/editor.

O fato de não se mapear nenhuma apresentação analógica nos textos que fazem referência à Linguística é surpreendente, uma vez que analogias são figuras de linguagem.

Verificou-se que a grande maioria das apresentações analógicas utiliza análogo extraído da vivência cotidiana das pessoas, o que era de se esperar, uma vez que os textos passam por um processo de editoração.

De acordo com a análise do grau de concordância com o modelo TWA, pode-se inferir que a maioria dos autores não explicita as correspondências entre análogo e alvo, nem identifica as limitações das analogias: das 136 apresentações analógicas catalogadas, em apenas $1,5 \%$ delas os autores identificam tais limites, propiciando, assim, que os leitores estabeleçam correspondências que não são equivalentes entre análogo e alvo. Este fato leva a crer que os autores não consideram relevante identificar os limites de validade das analogias, ou acham que tais limites são óbvios.

Tendo em vista os resultados obtidos, pode-se afirmar que as analogias têm sido pouco exploradas, quanto ao seu potencial didático, deixando, assim, de contribuírem tanto quanto poderiam para a aprendizagem dos leitores.

Uma das contribuições deste trabalho diz respeito à avaliação de textos que fazem uso de analogias publicadas em revistas. Como a revista Ciência Hoje das Crianças é utilizada pelos professores como material de apoio em aulas de ciências, eles, utilizando as contribuições do presente trabalho, podem avaliar quais textos necessitariam mais de suas contribuições pessoais para atenderem aos objetivos propostos, ao serem utilizados.

Há necessidade de novas pesquisas que investiguem a influência de textos que fazem uso de analogias na aprendizagem das crianças. Portanto, este trabalho pode ser um ponto de partida para novos estudos a serem realizados neste campo.

\section{Referências}

CARNEIRO, M. H. S. As imagens no livro didático. In: ENCONTRO NACIONAL DE PESQUISA EM ENSINO DE CIÊNCIAS, 1., 1997, Lindóia. Anais... Lindóia: ABRAPEC, 1997. 1 cd-rom.

CURTIS, R. V.; REIGELUTH, C. M. The use of analogies in written text. Instructional Science, New York, v. 13, n. 2, p. 99-117, 1984.

DUIT, R. On the role of analogies and metaphors in learning science. Science Education, Pennsylvania, v. 79, n. 6, p. 649-672, 1991.

ENCARNAÇÃO, B. Criança e Ciência: o relato de uma relação possível e de muito entusiasmo. Ciência e Ambiente, Santa Maria, s/v, n. 23, p. 99-113, 2001.

ESQUIBEL, M. A. A água e as plantas. Ciência Hoje das Crianças, São Paulo, v. 9, n. 60, p. 8-10, 1996. 
Silva, L. L.; Pimentel, N. L.; Terrazzan, E.

GODOY, L. A. Success and problems with analogies in teaching mechanics. Journal of Science Education, Pennsylvania, v. 3, n. 1, p. 11-14, 2002.

HARRISON, A. G.; TREAGUST, D. F. Teaching with analogies: a case study in grade-10 optics. Journal of Research in Science Teaching, Michigan, v. 30, n. 10, p. 1291-1307, 1993.

LAWSON, A. E. The importance of analogy: a prelude to the special issue. Journal of Research in Science Teaching, Michigan, v. 30, n. 10, p. 1213-1214, 1993.

LONDRES, H. Maionese: emulsão também se come. Ciência Hoje das Crianças, São Paulo, v. 10, n. 69, p. 23-25, 1997.

MASSARANI, L. Textos científicos para crianças. In: CONGRESSO DE LEITURA DO BRASIL, 2., 1999, Campinas. Anais... Campinas: ALB, 1999. p. 61-73.

MORA, A. M. S. La divulgación de la ciencia como literatura. México: Universidad Autónoma de México, 1998.

PINTO, V. S. Eles têm a força. Ciência Hoje das Crianças, São Paulo, v. 12, n. 95, p. 8-11, 1999.

QUEIROZ, G. R. P. C. Professores artistas-reflexivos de física no Ensino Médio. 2000. 461f. Tese (Doutorado em Educação) - Departamento de Educação, Pontifícia Universidade Católica do Rio de Janeiro, Rio de Janeiro, 2000.

SOUSA, G. G. A divulgação científica para crianças: o caso da Ciência Hoje das Crianças. 2000. 312f. Tese (Doutorado em Educação Gestão e Difusão em Biociências) Instituto de Ciências Biológicas, Universidade Federal do Rio de Janeiro, Rio de Janeiro, 2000 .

THIELE, R. B.; TREAGUST, D. F. Analogies in chemistry textbooks. International Journal of Science Education, Reading, v. 17, n. 6, p. 783-795, 1995.

TREAGUST, D. F.; DUIT, R.; JOSLIN, P.; LINDAUER, I. Science teacher's use of analogies: observations from classroom practice. International Journal of Science Education, Reading, v. 14, n. 4, p. 413-422, 1992. 
As analogias na revista de divulgação ...

Anexo 1. Extrato de quadro-síntese do levantamento das apresentações analógicas identificadas na revista Ciência Hoje das Crianças.

\begin{tabular}{|c|c|c|c|c|c|c|}
\hline $\begin{array}{l}\text { Código da } \\
\text { apresentação } \\
\text { analógica }\end{array}$ & $\begin{array}{l}\text { Autor(es) } \\
\text {. Ano } \\
\text {. Número } \\
\text {. Data } \\
\text {. Página(s) } \\
\text {. Txt/Fig/Leg }\end{array}$ & Seção & $\begin{array}{l}\text { Conceitol } \\
\text { temátical } \\
\text { assunto }\end{array}$ & $\begin{array}{c}\text { Situação } \\
\text { apresentada, } \\
\text { sugerida ou } \\
\text { subentendida }\end{array}$ & $\begin{array}{c}\text { Situação } \\
\text { análoga ou } \\
\text { analogia } \\
\text { utilizada }\end{array}$ & $\begin{array}{c}\text { Relações } \\
\text { analógicas } \\
\text { pretendidas }\end{array}$ \\
\hline $\mathrm{CHC} 79$ & $\begin{array}{l}\text { Carlos F. S. } \\
\text { Andrade, } \\
\text { Luciana U. dos } \\
\text { Santos e Rejane } \\
\text { Cristina } \\
\text { Brassolatti } \\
\text {. } 1998 \\
\text {. N. } 80 \\
\text {. Maio } \\
\text {. p. } 20 \\
\text {. Txt / Fig }\end{array}$ & $\begin{array}{l}\text { A batalha } \\
\text { contra os } \\
\text { pernilongos }\end{array}$ & $\begin{array}{l}\text { Transmissão } \\
\text { do vírus da } \\
\text { dengue }\end{array}$ & $\begin{array}{l}\text { Um pernilongo } \\
\text { pousando na } \\
\text { pele de uma } \\
\text { pessoa, } \\
\text { retirando o } \\
\text { sangue do seu } \\
\text { organismo. }\end{array}$ & $\begin{array}{l}\text { Uma injeção } \\
\text { para tirar } \\
\text { sangue }\end{array}$ & $\begin{array}{l}\text {. Injeção/ } \\
\text { Pernilongo } \\
\text {. Agulha/ } \\
\text { aparelho } \\
\text { bucal do } \\
\text { pernilongo }\end{array}$ \\
\hline $\mathrm{CHC} 92$ & $\begin{array}{l}\text {. Verônica S. } \\
\text { Pinto } \\
.1999 \\
\text {. N. } 95 \\
\text {. Setembro } \\
\text {. p. } 10 \text { - } 11 \\
\text {. Txt / Fig }\end{array}$ & $\begin{array}{l}\text { Eles têm a } \\
\text { força }\end{array}$ & $\begin{array}{l}\text { Funcionamento } \\
\text { dos músculos }\end{array}$ & $\begin{array}{l}\text { Os músculos } \\
\text { de uma pessoa } \\
\text { trabalhando }\end{array}$ & $\begin{array}{l}\text { Automóvel } \\
\text { composto de } \\
\text { um motor com } \\
\text { combustível, } \\
\text { pneus, e uma } \\
\text { carroceria. }\end{array}$ & $\begin{array}{l}\text {. Automóvel/ } \\
\text { Corpo } \\
\text { Humano } \\
\text {. Motor/ } \\
\text { Músculos } \\
\text {. Combustível/ } \\
\text { Energia dos } \\
\text { alimentos } \\
\text {. Pneus, } \\
\text { carroceria/ } \\
\text { Ossos }\end{array}$ \\
\hline
\end{tabular}

